\title{
Pasif Sigara İçiciliğinin Çocuklarda Sistemik ve Ağız-Diş Sağlı̆ı̆ına Etkisi
}

\author{
Solmaz Mobaraki(0000-0001-8740-0792) ${ }^{\alpha}$, Aysun Avşar(0000-0003-3911-4526) ${ }^{\beta}$
}

Selcuk Dent J, 2021; 8: 881-887 (Doi: 10.15311/selcukdentj.773109)

Başvuru Tarihi: 24 Temmuz 2020 Yayına Kabul Tarihi: 05 Kasım 2020

öz

Pasif Sigara İçiciliğinin Çocuklarda Sistemik ve Ağız-Diş Sağlığına Etkisi

Büyük bir halk sağlığı problemi olan pasif sigara içiciliği, uterusta bașlayabilir ve dogumdan sonra çocukluk döneminde de devam edebilir. Dünya Sağlık Örguitu'nün (DSÖ) verilerine göre yaklașk 700 milyon çocuk 1,2 milyar sigara kullanıcısı tarafından çogunlukla evde olmak üzere sigara dumanına maruz bırakılmaktadır. Pasif sigara içiciliği çocuklarda genel ve ağız sağlığı üzerinde olumsuz etkilere sahiptir. En sık neden olduğu sistemik hastalıklar; fetal malformasyon ve gelişme geriliği, ani bebek ölüm sendromu, prematür doğum, baş çevresi ölçümünde azalma, orta kulak enfeksiyonu, solunum yolu hastalıkları, dikkat eksikliği ve hiperaktivite bozukluğu, kardiyovasküler hastalıklar, diyabet, çocukluk çağı kanserleri, nörogelişimsel bozukluklardır. Ağızdiş sağlığında diş çürüğü, peridontal hastalıklar, gecikmiş dental gelişim, yarık dudak ve damak görülme sıklığı üzerine olumsuz etkileri vardır. Bu derleme, çocukların pasif sigara içiciliğine maruz kalmasının bu çeşitli sistemik ve dental problemler ile bağlantılı olduğunu vurgulamaktadır. Bu derlemenin sonucunda ebeveynlerin pasif sigara içiciliği konusunda erken eğitiminin önemli olduğu düşünülmektedir.

\section{ANAHTAR KELIMELER}

Pasif sigara içiciliği, Sistemik hastalıklar, Ağız-diş sağığı, Çocuk

Tütün üretimi ve kullanımına WHO (2002), verilerine göre ilk kez milattan önce 6000 yıllarında Amerika kıtasında başlanmıştır. ${ }^{1}$ Bu tarihten 4500 yıl sonra Mayaların tütün kullandığı tarih kitaplarında yer almaktadır. Avrupalılar tütünü, 1492 yılında Küba'ya ayak basan Christopher Columbus sayesinde öğrenmiştir. Yerliler dini törenlerde ve şölenlerde keyifle içtikleri tütünü Avrupa'dan gelen denizcilere de ikram etmişler ve Tobacos olarak tanıtmışlardır. Tütün yapraklarının çiğnenmesi, tozunun yaralara sürülmesi, lavman olarak kullanılması o dönemdeki başlıca tütün kullanım şekilleri olarak bilinmektedir. ${ }^{2}$

\section{Sigaranın İçeriği}

Sigara, tütün olarak bilinen bitkilerin yapraklarından elde edilen ve pek çok insanın keyif verdiğini düşündüğü bir maddedir. Sigara, bilinen ve insan davranışlarını etkileyen en yaygın ve en etkili alışkanlıklardan birisidir. Sigaranın kimyasal içeriğinde, bağlayıcı, tatlandırıcı, doldurucu, koruyucu, çözücü ve nemlendirici olarak çoğu kimyasal olan madde karşımıza çıkmaktadır.

\section{ABSTRACT}

An Effect of Passive Smoking on General and Oral Health of Children

The adverse effects of passive smoking, as a significant public health hazard, can begin in early fetal life in the uterus and proceed on childhood. Based on the data provided by the World Health Organization (WHO) in 2009, almost 700 million kids had been exposed to tobacco smoke by 1.2 billion smokers in their households. Although the dangerous side effects of passive smoking can be seen in different age groups, the first and foremost adverse effect has been reported in children. The variety of health complications, including the dental problem, are related to passive smoking in children. Serious fetal malformations, developmental retardation, Sudden Infantile Death Syndrome (SIDS), premature birth, decreased head circumference size, otitis media, pulmonary disease, Attention Deficit and Hyperactivity Disorder(ADHD), cardiovascular disease, diabetes, different types of childhood çancers are most systemically disorders in passive smoker children. On the other hand, dental caries, periodontal diseases, delayed dental deveoplment, cleft lip and cleft palate are mostly reported in these groups. In this study, we review the relation of passive smoking with the general and dental problems among the children who have been exposed to tobacco smoke. The results support the critical importance of the topic as a public health awareness and demonstrate the necessity of early parental education.

\section{KEYWORDS}

Passive smoking, Systemical disorder, Oral-dental health, Child

Sigaranın içeriğinde tatlandıııcı olarak; asetanizol, asetik asit, aseton, asetofenon, balzam yağı, benzaldehid, koruyucu olarak; sorbik asit, potasyum sorbat, benzoik asit, doldurucu olarak; kalsiyum karbonat, bağlayıcı olarak; karboksimetil selüloz ve selüloz, çözücü olarak; solvent, nemlendirici olarak; gliserol ve sorbitol bulunmaktadır. ${ }^{3-4}$

\section{Pasif Sigara İçiciliğinin Epidemiyolojisi}

Çevresel sigara dumanı, ABD Çevre Koruma Ajansı (EPA) (1992) raporlarına göre sigaranın yanması ile açığa çıkar ve doğrudan sigarayı içen kişi veya kişiler dışındaki bireylerin soluduğu havayı oluşturur. Sigara içmeyen kişinin kapalı ya da açık alanlarda, ÇSD maruz kalarak tüm zararlı maddelerin solunması "pasif sigara içiciliği" olarak tanımlanmaktadır. ${ }^{5}$ Dünya Sağlık Örgütü (WHO) 2009 raporuna göre dünya üzerinde (WHO) 700 milyon çocuğun 1.2 milyar sigara kullanıcısı tarafından çoğunlukla evde olmak üzere sigara dumanına maruz bırakıldığı, kadınların \%35'i ve erkeklerin \%33'ünün kapalı alanlarda

\footnotetext{
${ }^{\alpha}$ Van Yüzüncü Yıl Üniversitesi Diş Hekimliği Fakültesi, Pedodonti AD, Van, Türkiye

$\beta$ Ondokuz Mayıs Üniversitesi Diş Hekimliği Fakültesi, Pedodonti AD, Samsun, Türkiye
} 
pasif sigara içicisi olduğu belirtilmiştir. ${ }^{6-7}$ Ülkemizde pasif sigara içicisi olan çocukların oranı ile ilgili geniş çaplı çalışmalar olmamasına rağmen, yapılan çalışmalarda çocuklarda pasif içicilik oranının \%34-86 arasında olduğu belirtilmiştir. ${ }^{8-9}$

\section{Pasif İçiciliğin Ölçümü}

Pasif sigara içiciliğinin değerlendirilmesinde çeşitli yöntemler kullanılmaktadır. Sigara dumanına maruz kalmanın değerlendirilebilmesi için ideal bir yöntem bulunmamakla birlikte sigara dumanı ile ilişkili risklerin doğru bir şekilde değerlendirilebilmesi doğru ölçümlere bağlıdır. ${ }^{10}$ Pasif sigara içiciliğinin ölçümü; kişilerin maruz kaldığı havadaki sigara dumanı bileşenlerinin ölçülmesi, vücuttaki sigara dumanı bileşenlerinin konsantrasyonlarının ölçülmesi, anket veya görüşmelerde maruz kalmanın kişi tarafından bildirilmesi yoluyla tespit edilmektedir Prenatal dönemdeki çalışmalarda annenin idrar, tükürük, saç örneğinde ve fetal kordon kanından kotinin ölçümü yapılmaktadır. Postnatal dönemde ise çocuğun idrar, kan ve tükürük yapısındaki kotinin miktarı ölçümünün yanı sıra, çocuğun saç örneğindeki kotinin değerleri incelenmektedir. ${ }^{10-15}$

İyi bir ölçü yöntemi; kolay olmalı, süresi ve sıklığı temsil edebilmeli, kaynağın gücü ile değişebilmeli, sigara dumanına özel, düşük konsantrasyonlarda bile tespit edilebilmeli ve makul bir mal oluşla kolay ve doğru bir şekilde ölçüm yapabilmelidir. Bileşenlerin ölçüm yöntemlerinin pahalı ve zaman alıcı olması ve özel ekipman gerektirmesi nedeniyle geniş popülasyonu kapsayan çalışmalarda en sık olarak, aktif ya da pasif sigara içiciliğin yazılı veya sözlü iletişim ile kişisel bildirim ile değerlendirilen anket çalışmaları tercih edilmektedir. ${ }^{14-15}$

\section{Pasif Sigara İçiciliğinin Çocukların Sistemik Sağlığı Üzerine Etkisi}

WHO (2009) raporuna göre, pasif sigara dumanına maruz bırakılmanın güvenli seviyesi yoktur ve maruz bırakılma derecesine göre her yıl pasif sigara içiciliğine bağlı mortalitenin yaklaşık 600 bin olduğu ve \%28'ini çocukların oluşturduğu rapor edilmiştir. ${ }^{6-7}$

\subsection{Fetal Malformasyon ve Gelişme Geriliği}

Transplasental nikotine maruz kalma ile fetal malformasyonlardaki artış arasında pozitif bir ilişki olduğu bildirilmiştir. ${ }^{16}$ Hudson ve Timiras (1972) gebelik süresince sigara dumanına maruz kalan rat yavrularının beyin protein içeriği ve DNA'sında ve hücre sayısında azalma olduğunu bildirmişlerdir. Bu bulguyla birlikte; toksik etkilere ek olarak hücresel büyüme gecikmesine de neden olarak fetal gelişim geriliğinin oluştuğu rapor edilmiştir. ${ }^{17}$

\subsection{Ani Bebek Ölüm Sendromu ( $A B O ̈ S$ )}

ABÖS görünüşte sağlıklı 1 yaşından küçük bebeğin beklenmedik bir şekilde ve açıklanamayan nedenlerle, çoğunlukla uyku sırasında gelişen ani ölümüdür.
Annenin hamilelikte sigara içmesi nedeniyle ABÖS gelişmesi mekanizması tam olarak bilinmemekle birlikte kronik fetal hipoksik strese ve anormal akciğer ve beyin gelişimine yol açan morfolojik plasental değişikliklere neden olabileceği gibi birçok hipotez önerilmiştir. ${ }^{\text {8-19 }}$

\subsection{Prematür Doğum}

Prematür doğum, gebelik süresinin 37. haftasından önce gerçekleşen ve/veya bebeğin doğum ağırlığının 2500 gr'ın altında olduğu doğumlar olarak tanımlamaktadır. Annenin hamilelikte aktif ve/veya pasif sigara içici olmasıyla sigara dumanındaki toksik kimyasallar fetüsün kan akışını, oksijenasyonunu, enzim ve protein aktivitesini etkileyerek prematüre doğum için risk faktörü olabilmektedir. ${ }^{19-21}$

\subsection{Baş Çevresi Ölçümü}

Çocukların baş çevresi ölçüm miktarının doğum öncesi dönemde pasif sigara içici olup olmamasına göre etkilenebileceği belirtilmiştir. Pasif sigara içici çocukların baş çevresi ölçümü üzerindeki etkisi sadece çocukluk ile sınırlı olmayıp bu nörolojik etkilerin neden olduğu eksiklikler yaşam boyunca devam etmektedir. Fetal yaşam, bebeklik ve erken çocukluk döneminde bozulmuş beyin gelişimi ve büyümesi, yaşlılarda kognitif fonksiyonların azalması ile ilişkilidir. ${ }^{22-23}$

\subsection{Orta Kulak Enfeksiyonu}

Pasif sigara içici olan bebeklerde, pasif içici olmayan bebeklere göre daha sık orta kulak enfeksiyonu geçirdiği, iyileşme süresininde 1,5 kat daha uzattığı görülmüştür. Pasif içicilik, mukosiliyer fonksiyonun bozulmasına ve fazla miktarda mukus birikmesine bağlı olarak nazofaringeal hava yolunun tıkanmasına neden olmaktadır. Lokal immün fonksiyonun baskılanarak orta kulağa mikroorganizma invazyonunun artması, orta kulak hastalığının başlangıcındaki patojenik mekanizma olarak gösterilmektedir. ${ }^{24-25}$

\subsection{Solunum Yolu Hastalıkları}

Nikotin plasentayı geçip fetal akciğerdeki nikotinik asetilkolin reseptörlerini uyararak fetusun akciğer yapı ve fonksiyonlarında değişiklikler meydana getirmektedir. Bronşiyal epitelyum yüzeyindeki nikotinik asetilkolin reseptörleri ile nikotinin etkileşmesi, hücre proliferasyonunu başlatarak ve akciğer büyümesini olumsuz yönde etkileyerek solunum sistemi üzerine olumsuz etkisi göstermektedir. Çevresel tütün dumanına maruz kaldığı için yılda 300,000-1,500,000 civarında çocuğun alt solunum yolu enfeksiyonu geçirdiği ve 200,000$1,000,000$ çocukta da astım ataklarının sıklığının ve şiddetinin arttığı bildirilmiştir. ${ }^{26-27}$ 


\subsection{Dikkat Eksikliği ve Hiperaktivite Bozukluğu (DEHB)}

Gebelikte annenin sigara içmesinin DEHB için bugüne kadar tespit edilen en önemli risk faktörü olduğu bulunmuştur ve bu annelerin "hiperkinetik" çocuk sahibi olma olasılığının 3 kat daha fazla olduğu bildirilmiştir. Ayrıca pasif sigara içicisi olan çocuklarda DEHB ve benzer davranış bozuklukları 2.4 ila 3.4 kat daha yüksek oranda bildirilmiştir. ${ }^{28-29}$

\subsection{Kardiyovasküler hastalıklar}

Konjenital kalp defektleri en yaygın görülen doğum defektidir ve bebeklik ve çocukluk çağı ölümlerinin en büyük sebebidir. Hamilelik sırasında sigara içen annelerin çocuklarında konjenital kalp defeki görülme sıklığı artmaktadır. Sigaranın ana maddesi olan nikotin santral ve periferik sinir sisteminde katekolamin ve diğer nörotransmitterleri salgılatarak sempatik uyarı yapmaktadır. Kalp atım hızını, kan basıncını ve kardiyak debiyi yükselterek kardiyovasküler dokular üzerinde etki yapmaktadır. Ayrıca, düşük yoğunluklu lipoproteinde artışa ve serbest yağ asitlerini harekete geçirerek yüksek yoğunluklu lipoproteinin azalmasına neden olarak, vazokonstriksiyonu arttırır ve kan epitel hücre hasarını ve aterosklerozu hızlandırır. Sigara dumanınında bulunan nitröz oksit ise hemoglobine bağlanmasıyla oluşan hipoksiye cevap olarak gelişen, kan hücrelerinin sayıca artmasıyla artan kan viskozitesi doğrudan ateroskleroz oluşumu üzerinde etkilidir. ${ }^{30-32}$

\subsection{Diyabet}

Pasif sigara içicilikte obeziteye bağlı insülin direncinde olduğu gibi inflamatuar tepkiler görülmektedir. Pasif sigara içici olan farelerin kan örneklerinde, yüksek düzeyde DNA hasarı, değişen lipid ve lipoprotein yapıları, süperoksit dismutaz aktivitesinde azalma olduğu görülmüştür. ${ }^{33}$

\subsection{0. Çocukluk Çağı Kanserleri}

Sigara dumanının içerdiği kanserojen maddeler sebebiyle pasif sigara içici çocuklarda kanser riski artmaktadır. Pasif sigara içiciliğinin çocukluk çağı kanserinin etiyolojisinde etkisi daha az olmasına rağmen, sigara içen annelerin yenidoğan bebeklerinde, kromozomal bozulma sıklığının artması ve oksidatif hasar görülmektedir. Sigara dumanının tümör baskılayıcı gen olan P53'ü inhibe etmesi, nikotin ve katranın tümör hücrelerini kontrol eden $T$ hücresini baskılaması, hepatositlerde fibroziye yol açması ve içerdiği serbest radikallerin doğrudan DNA'yı okside ederek hücresel hasara neden olması nedeniyle kanserojenitede önemli bir rol oynamaktadır. ${ }^{34-36}$

\section{Ağız ve Diş Sağlığı Üzerine Etkisi \\ 5.1. Diş Çürüğü}

Günümüze kadar yapılan araştırmalarda, çocuklarda pasif sigara içiciliği ile çürük arasında pozitif bir ilişki olduğu belirtilmiştir. ${ }^{37-46}$ Ülkemizde de pasif sigara içiciliğinin çürük oluşumuna etkisi, biyokimyasal, mikrobiyolojik ve klinik yöntemler kullanılarak ortaya konulmuştur. ${ }^{45-46}$

Pasif sigara içiciliğin çocuklarda Streptococcus mutans (S.mutans) sayısında artışa neden olması çürük sıklığında en önemli etkendir. Bu etkende birçok mekanizma rol oynamaktadır. Öncelikle, pasif sigara içiciliği immun sistemin baskılanmasında veya değişmesinde hazırlayıcı bir rol oynayarak karyojenik mikroorganizmaların sayısını arttırabilmektedir. Aktif sigara içici olan annenin bebeğini emzirmesiyle toksik maddeler çocuğa ağız yoluyla geçerek, erken S. mutans kolonizasyonu sonucu dişleri çürüğe daha yatkınlaşmasına neden olmaktadır. ${ }^{43-47}$ Ayrıca pasif sigara içici çocuklarda, C vitamini değerinin azalmasının S.mutans çoğalmasıyla ilişkili olduğu gösterilmiştir. ${ }^{48}$

Diğer bir etken, pasif sigara içiciliğinin tükürük bezinin fonksiyonunu ve anatomik yapısını etkileyerek tükürüğün tamponlama kapasitesini düşürmesi, IgA seviyesini azaltması, amilaz aktivitesi ve sialik asit seviyesini arttırmasıdır. ${ }^{46,49-51}$ Tükürük komponentlerindeki bu değişiklikler, S.mutans kolonizasyonunda artış meydana getirmekte ve bu durumda fermente olabilen karbonhidratların ağız içerisinden uzaklaştırılmasını olumsuz yönde etkilenmektedir. ${ }^{46}$ Ayrıca tükürükte interlökin-1 $\beta$, laktoferrin, albümin ve aspartat aminotransferaz da dahil olmak üzere inflamatuar belirteçlerin konsantrasyonu pasif içicilerde artmaktadır. ${ }^{51-53}$

Yapılan çalışmalarda prenatal pasif sigara içiciliğinin EÇÇ gelişimi için bir risk faktörü olduğu belirtilmiştir. ${ }^{43-}$ ${ }_{45,54} \mathrm{Bu}$ görüşte, prenatal pasif sigara içiciliğinin erken doğum ve düşük doğum ağırlığı için önemli bir risk faktörü olması öne çıkmaktadır.20-21 Ayrıca düşük doğum ağırığının dişlerde gelişimsel bozukluklara yol açarak, EÇÇ'ye yatkınlığı arttırdığı da rapor edilmiştir. ${ }^{55}$

Aktif sigara içici olan annelerin çocuklarının emzirme süresinin kısa olduğu bazı çalışmalarda bildirilmiştir. Anne sütü alımının kısa süreli olması, biberon kullanımı gibi kötü beslenme alışkanlıklarını beraberinde getirmektedir. Bir yașından sonra biberon kullanımı, bebegin uzun süreli ve/ veya sık aralıklarla emzirilmesi, çocugun biberonla uyumasına izin verilmesi gibi uygun olmayan beslenme alışkanlıkları, süt dișlerinin fermente olabilen karbonhidratlara maruz kalma süresini artırmaktadır. Bu artıs, hem oral S.mutans'ların erken kolonizasyonunu tetiklemekte hem de mikrobiyal dental plak ve tükürükteki S. mutans sayılarını arttırarark EÇÇ riskini artırmaktadır. ${ }^{56}$

Eğitim seviyesi düşük olan aktif içici ebeveynlerin fırçalama alişkanliklarinin yetersiz ve beslenme alışkanlıklarının kötü olduğu çalışmalarla gösterilmiştir. ${ }^{57-58} \mathrm{Bu}$ ebeveynlerin çocuklarının diş fırçalama alışkanlıklarının daha düşük olduğu, diş fırçalama konusunda daha az yardım aldığı ve geceleri ara öğünleri daha fazla tükettiği için çürük görülme 
sıklığı önemli oranda arttırdığı bilinmektedir. ${ }^{37-38,40-41}$

\subsection{Periodontal Dokular Üzerindeki Etkisi}

Pasif sigara içiciliği periodontal dokular üzerinde aktif sigara içiciliğine benzer etkiler oluşturmaktadır. Sigara dumanı ve bileşenlerinin neden olduğu vazokonstriksiyona bağlı oluşan oksijen miktarının azalması, subgingival anaerobik bakteri kolonizasyonu ve biyofilm oluşumuna yol açmaktadır. Böylece periodontal hastalığın progresyonunu artırabilen gram negatif anaerobik periodontal patojenlerden olan Actinobacillus actinomycetemcomitans, Prevotella intermedia, Prevotella nigrescens, Treponema denticola ve Porphyromonas gingivalis, Staphylococcus aureus, Klebsiella pnömonisi ve Pseudomonas aeruginosa tarafından üretilen toksinlerin gücü artmaktadır. ${ }^{59-62}$ Ayrıca karbon monoksit nedeniyle doku oksijenasyonu ve revaskülarizasyonunu bozmakta, immün ve inflamatuar cevapları etkileyerek periodontal doku iyileşmesini geciktirmektedir. ${ }^{63-64}$

Periodontal dokularda görülen bir diğer değişiklik, aktif ve pasif içicilik sonucunda melanin birikmesine bağlı olarak genellikle üst çenede ön kesici dişler bölgesi papillalarında dişeti pigmentasyonuna neden olmasıdır. ${ }^{65}$

\subsection{Diş ve Çene Gelişimi Üzerine Etkisi}

Prenatal dönemde pasif sigara içiciliğine maruz kalınması, epitelyal ve mezanşimal komponentlerin bütünlüğü bozulmasına sebep olabileceği için, genel ve kraniyofasiyal büyüme de olumsuz yönde etkileyebilmektedir. Bunun sonuncunda, kesici dişlerin odontogenezisi ve çenelerin gelişiminde gecikme meydana gelirken; dişlerin gelişiminde gecikme, süt ve daimi diş boyutlarında boyutunda azalma (hipodonti), diş yüzeyinde opasiteler görülmektedir. ${ }^{66-69}$

\subsection{Yarık Dudak ve Damak}

Genler ve çevresel faktörlerin etkisi sonucunda, ölümcül olmayan kraniofasiyal doğum defekti olarak bilinen oral yarıklar; yarık dudak, yarık damak, yarık dudak-damak şeklinde görülmektedir. Etiyoloji ve patogenezinde ağırlıkı rol oynayan risk faktörlerinin etkileşimi tam olarak bilinmemekle birlikte, yapılan çalışmalarda, annenin gebelik döneminde aktif ve pasif sigara içicisi olmasının, non-sendromik oral yarıklar için risk faktörlerinden biri olduğu belirtilmiştir. ${ }^{70-71}$

\section{SONUÇ}

Pasif sigara içiciliği genel sağlığı etkilemekle birlikte, ağız, diş ve çene gelişimini etkileyen önemli bir halk sağlığı sorunudur. Kapalı mekanlarda sigara içmeyenlerin tütün dumanından pasif etkileniminin önlenmesi birçok ülkede yasalarca düzenlenmiştir. Fakat yasaların kapsamadığı çocukların ve yetişkinlerin zamanlarının çoğunu harcadığı ev, araba ortamında sigara dumanından pasif etkilenme halen devam edilmektedir. Bu yüzden ebeveynlerin pasif sigara içiciliği konusunda erken eğitimi önem taşımaktadır.

Tablo 1.

\section{Pasif Sigara İçiciliğinin Çocukların Sistemik ve Dental Sağlığı Üzerine Etkisi:}

\begin{tabular}{|c|c|}
\hline Sistemik Sağlığı Üzerine Etkisi & Ağız ve Diş Sağlığı Üzerine Etkisi \\
\hline $\begin{array}{l}\text { Fetal Malformasyon ve Gelişme } \\
\text { Geriliği }\end{array}$ & $\begin{array}{l}\text { Diş Çürüğü ve Erken Çocukluk Çağı Çürüğün } \\
\text { artması }\end{array}$ \\
\hline Ani Bebek Ölüm Sendromu & Periodontal Doku İyileşmesinde Geciktirme \\
\hline Prematür Doğum & Dişeti Pigmentasyonuna \\
\hline Baş Çevresi Ölçümü & Kesici Dişlerin Odontogenezisi \\
\hline Orta Kulak Enfeksiyonu & Çenelerin Gelişiminde Gecikme \\
\hline Solunum Yolu Hastalıkları & Dişlerin Gelişiminde Gecikme \\
\hline $\begin{array}{l}\text { Dikkat Eksikliği ve Hiperaktivite } \\
\text { Bozukluğu }\end{array}$ & $\begin{array}{l}\text { Süt ve Daimi Diş Boyutlarında Boyutunda azalma } \\
\text { (Hipodonti) }\end{array}$ \\
\hline Kardiyovasküler Hastalıklar & Diş Yüzeyinde Opasiteler \\
\hline Diyabet & Yarık Dudak ve Damak \\
\hline
\end{tabular}




\section{KAYNAKLAR}

1. Mackay J., Eriksen M. The Tobacco Atlas. WHO. 2002.

2. BAT 2010. Tütünün http://www.bat.com.tr/group/sites/, 2019.

3. Hoffmann D, Hoffmann I. The changing cigarette, 1950-1995. J Toxicol Environ Health. 1997;50(4):30764.

4. Hoffmann, D, Hoffmann, I. Tobacco smoke components. Betir. Tabak. Int. 1998;18, 49-52.

5. Guerin M.R. Jenkins R.A.ve Tomkins B.A. The Chemistry o f Environmental Tobacco Smoke: Composition and Measurement, Eisenberg, M. The Chemistry of Environmental Tobacco Smoke: Composition and Measurement. 2th Ed., Chelsea, Lewis Publishers, 1992, 49-69.

6. WHO, Report on the global tobacco epidemic. https://www.who.int/tobacco/mpower/2009/en/,2019.

7. Oberg M, Jaakkola MS, Woodward A, Peruga A, Prüss-Ustün A. Worldwide burden of disease from exposure to second-hand smoke: a retrospective analysis of data from 192 countries. Lancet. 2011; 377(9760):139-46.

8. Boyaci $\mathrm{H}$, Etiler $\mathrm{N}$, Duman C, Basyigit I, Pala A. Environmental tobacco smoke exposure in school children: parent report and urine cotinine measures. Pediatr Int. 2006; 48(4):382-9.

9. Ekerbiçer HC, Çelik M, Güler E, Davutoğlu M, Kılınc M. Evaluating environmental tobacco smoke exposure in a group of Turkish primary school students and developing intervention methods for prevention. BMC Public Health 2007; 7: 202.

10. Jaakkola MS, Jaakkola JJ. Assessment of exposure to environmental tobacco smoke. Eur Respir J 1997; 10: 2384-2397.

11.Florescu A, Ferrence R, Einarson T, Selby $P$, Soldin $O$, Koren $G$. Methods for quantification of exposure to cigarette smoking and environmental tobacco smoke: focus on developmental toxicology. Ther Drug Monit 2009; 31(1): 14-30.

12.Polanska K KA, Merecz-Kot D, Ligocka D, Mikolajewska K, Mirabella F, Chiarotti F, Calamandrei G, Hanke W. Environmental Tobacco Smoke Exposure during Pregnancy and Child Neurodevelopment. Int J Environ Res Public Health. 2017; 14(7).

13.Li Z LZ, Zhang J, Huo W, Zhu Y, Xie J, Lu Q, Wang B. Using nicotine in scalp hair to assess maternal passive exposure to tobacco smoke. Environ Pollut. 2017; 222:276-282.
14. Robinson O MD, Aurrekoetxea JJ, Estarlich M, Somoano AF, Íñiguez C, Santa-Marina L, Tardón A, Torrent M, Sunyer J, Valvi D, Vrijheid M. The association between passive and active tobacco smoke exposure and child weight status among Spanish children. Obesity (Silver Spring). 2016; 24(8):1767-77.

15.Wu H CT, Ma Q, Xu X, Xie K, Chen Y. Associations of maternal, perinatal and postnatal factors with the eruption timing of the first primary tooth. Sci Rep. 2019; 9(1):2645.

16. Luck W, Nau H, Hansen R, Steldinger R. Extent of nicotine and cotinine transfer to the human fetus, placenta and amniotic fluid of smoking mothers. Dev Pharmacol Ther. 1985;285:931945.

17. Hudson DB, Timiras PS. Nicotine injection during gestation: impairment of reproduction, fetal viability, and development. Biol Reprod. 1972; 7(2):247-253.

18.Zhang $\mathrm{K}$, Wang $\mathrm{X}$. Maternal smoking and increased risk of sudden infant death syndrome: a meta-analysis. Leg Med (Tokyo). 2013;15(3):115-21.

19. Torchin H, Lous ML, Houdouin V.Gynecol Obstet Fertil Senol. In utero exposure to maternal smoking: Impact on the child from birth to adulthood - CNGOF-SFT Expert Report and Guidelines on the management of smoking during pregnancy. 2020 Apr S24687189(20)30139-2

20.Vicedo- Vicedo-Cabrera AM, Schindler C, Radovanovic D, Grize L, Witassek F, Dratva J, Röösli M, Perez L.Benefits of smoking bans on preterm and early-term births: a natural experimental design in Switzerland. Tobacco Control 2016;25:e135-e141.

21.Ion, R., \& Bernal, A. L. Smoking and Preterm Birth. Reproductive Sciences,2014; 22(8): 918926.

22. Roza SJ, Verburg BO, Jaddoe VW, Hofman A, Mackenbach JP, Steegers EA, Witteman JC, Verhulst FC, Tiemeier $\mathrm{H}$. Effects of maternal smoking in pregnancy on prenatal brain development. Eur J Neuro. 2007; (25): 611-617.

23.Zhou S, Rosenthal DG, Sherman S, Zelikoff J, Gordon T, Weitzman M. Physical, behavioral, and cognitive effects of prenatal tobacco and postnatal secondhand smoke exposure. Curr Probl Pediatr Adolesc Health Care. 2014; 44(8):219-41.

24. Bowatte G, Tham R, Perret JL, Bloom MS, Dong G, Waidyatillake N, Bui D, Morgan GG, Jalaludin B, Lodge CJ, Dharmage SC. Air Pollution and Otitis Media in Children: A Systematic Review of Literature. Int J Environ Res Public Health. 2018; 15(2). 
25.Zhang Y, Xu M, Zhang J, Zeng L, Wang Y, Zheng QY. Risk factors for chronic and recurrent otitis media-a meta-analysis. PLoS One. 2014; 9(1):e86397.

26. Fukuma M, Seto Y, Fukushima K, Sakurai T, Dan K, Fujita $\mathrm{H}$, Toyoshima $S$. The effect of food dye and other environmental substances on the host defense reaction in mice in relation to virus infection. $\mathrm{J}$ Toxicol Sci. 1986; $11(3): 169-77$.

27. Murphy TD. Passive Smoking and Lung Disease. https://emedicine.medscape.com/article/1005579treatment, 2018.

28. Linnet KM, Dalsgaard S, Obel C, Wisborg K, Henriksen TB, Rodriguez A, Kotimaa A, Moilanen I, Thomsen $\mathrm{PH}$, Olsen J, Jarvelin MR. Maternal lifestyle factors in pregnancy risk of attention deficit hyperactivity disorder and associated behaviors: review of the current evidence. Am J Psychiatry. 2003; 160(6):1028-40.

29. Schmitz M, Denardin D, Laufer Silva T, Pianca T, Hutz $\mathrm{MH}$, Faraone S, Rohde LA. Smoking during pregnancy and attention-deficit/hyperactivity disorder, predominantly inattentive type: a case-control study. J Am Acad Child Adolesc Psychiatry. 2006; 45(11):1338-45.

30. Hoffman Jl, Kaplan S, Liberthson RR. Prevalence of congenital heart disease. Am Heart J. 2004; 147(3):425-39.

31. Alverson CJ, Strickland MJ, Gilboa SM, Correa A. Maternal smoking and congenital heart defects in the Baltimore-Washington Infant Study. Pediatrics. 2011; 127(3):e647-53.

32. Ambrose JA, Barua RS. The pathophysiology of cigarette smoking and cardiovascular disease: an update. J Am Coll Cardiol. 2004;43(10):1731-7.

33.Damasceno DC, Sinzato YK, Bueno A, Dallaqua B, Lima PH, Calderon IM, Rudge MV, Campos KE. Metabolic profile and genotoxicity in obese rats exposed to cigarette smoke. Obesity (Silver Spring). 2013; 21 (8):1596-601.

34. Hecht SS. Tobacco carcinogens, their biomarkers and tobaccoinduced cancer. Nat Rev Cancer 2003;3:733-44.

35.Pluth JM, Ramsey MJ, Tucker JD. Role of maternal exposures and newborn genotypes on newborn chromosome aberration frequencies. Mutat Res. 2000; 465(1-2):101-11.

36.Wang $B$, Zhang $Y, X u D Z$, Wang $A H$, Zhang $L$, Sun CS, Li LS. Meta-analysis on the relationship between tobacco smoking, alcohol drinking and p53 alteration in cases with esophageal carcinoma. Zhonghua Liu Xing Bing Xue Za Zhi. 2004; 25(9):775-8.
37.Williams SA, Kwan SY, Parsons S. Parental smoking practices and caries experience in preschool children. Caries Res. 2000;34:117-22.

38. Aligne $C$, Moss $M$, Auinger $P$, Weitzman $M$. Association of pediatric dental caries with passive smoking. J Am Med Assoc. 2003;289:1258-64.

39. Billings RJ, Berkowitz RJ, Watson G. Teeth. Pediatrics. 2004; 113(4 Suppl):1120-7.

40. Shenkin JD, Broffitt B, Levy SM, Warren JJ. The association between environmental tobacco smoke and primary tooth caries. J Public Health Dent. 2004;64(3):184-6.

41. Tanaka K, Hanioka T, Miyake Y, Ojima M, Aoyama $\mathrm{H}$. Association of smoking in household and dental caries in Japan. J Public Health Dent. 2006;66:279-81.

42. Ayo-Yusuf OA, Reddy PS, van Wyk PJ, van den Borne BW. Household smoking as a risk indicator for caries in adolescents' permanent teeth. J Adolesc Health. 2007; 41(3):309-11.

43. Bernabe E, MacRitchie H, Longbottom C, Pitts NB, Sabbah W. Birth Weight, Breastfeeding, Maternal Smoking and Caries Trajectories. J Dent Res. 2017; 96(2):171-178.

44.Goto Y, Wada K, Konishi K, Uji T, Koda S, Mizuta F, Yamakawa M, Watanabe K, Ando K, Ueyama $\mathrm{J}$, Kondo T, Nagata C. Association between exposure to household smoking and dental caries in preschool children: a cross-sectional study. Environ Health Prev Med 2019;24(1):9

45. Avsar A, Darka O, Topaloglu B, Bek Y. Association of passive smoking with caries and related salivary biomarkers in young children. Arch Oral Biol. 2008;53:969-74.

46. Avşar A, Darka O, Bodrumlu EH, Bek Y. Evaluation of the relationship between passive smoking and salivary electrolytes, protein, secretory IgA, sialic acid and amylase in young children. Arch Oral Biol. 2009;54(5):457-63.

47. Lindemeyer, Rochelle G.Baum, Robert H.Hsu, Stephen C.Going, Robert E. et al. In Vitro Effect of Tobacco on the Growth of Oral Cariogenic Streptococci. The Journal of the American Dental Association1981; 103(5): 719 - 722

48. Strauss RS. Environmental tobacco smoke and serum vitamin $C$ levels in children. Pediatrics. 2001;107(3):540-2.

49. Roesink JM, Terhaard $\mathrm{CH}$. The influence of clinical factors on human stimulated parotid flow rate in cancer and other patients. Oral Oncol. 2002;38(3):291-5.

50. lida T, Ono K, Inagaki T, Hosokawa R, Inenaga K. Nicotinic receptor agonist-induced salivation and its cellular mechanism in parotid acini of rats. Auton Neurosci. 2011;161(1-2):81-6.

51.Ginzkey C, Kampfinger K, Friehs G, Köhler C, Hagen R, Richter E, Kleinsasser NH. Nicotine induces DNA damage in human salivary glands. Toxicol Lett. 2009;184(1):1-4. 
52. Nishida N, Yamamoto Y, Tanaka M, Kataoka K, Kuboniwa M, Nakayama K, Morimoto K, Shizukuishi S. Association between involuntary smoking and salivary markers related to periodontitis: a 2-year longitudinal study. J Periodontol. 2008; 79(12):223340.

53. Nishida N, Yamamoto $\mathrm{Y}$, Tanaka M, Maeda K, Kataoka K, Nakayama K, Morimoto K, Shizukuishi S. Association between passive smoking and salivary markers related to periodontitis. J Clin Periodontol. 2006; 33(10):717-23.

54. Masumo R, Birungi N, Bardsen A, Fadnes LT, Astrom AN. Impact of low birthweight on early childhood caries in 6-36 months old infants in Uganda: A crosssectional study. Acta Odontol Scand 2014; 72(4): 312-320.

55. Nelson S, Albert JM, Geng C, Curtan S, Lang K, Miadich S, Heima M, Malik A, Ferretti G, Eggertsson $H$, Slayton RL, Milgrom P. Increased enamel hypoplasia and very low birthweight infants. J Dent Res 2013; 92(9): 788-794.

56.Tinanoff, N, Baez, RJ, Diaz Guillory, C, et al. Early childhood caries epidemiology, aetiology, risk assessment, societal burden, management, education, and policy: Global perspective. Int J Paediatr Dent. 2019; 29(3): 238- 248.

57.Tanaka K MY, Sasaki S: The effect of maternal smoking during pregnancy and postna- tal household smoking on dental caries in young children. J Pediatr 2009;155(3):410-415.

58. Watanabe M, Wang DH, ljichi A, Shirai C, Zou Y, Kubo M, Takemoto K, Masatomi C, Ogino K. The influence of lifestyle on the incidence of dental caries among 3-year-old Japanese children. Int $\mathrm{J}$ Environ Res Public Health 2014; 11(12): 12611-12622.

59.Sayers NM, James JA, Drucker DB, Blinkhorn AS. Possible potentiation of toxins from Prevotella intermedia, Prevotella nigrescens, and Porphyromonas gingivalis by cotinine. J Periodontol. 1999; 70(11):1269-75.

60.Chen LC, Quan C, Hwang JS, Jin X, Li Q, Zhong M, Rajagopalan S, Sun $Q$. Atherosclerosis lesion progression during inhalation exposure to environmental tobacco smoke: a comparison to concentrated ambient air fine particles exposure. Inhal Toxicol. 2010; 22(6):449-59.

61. Sanders AE, Slade GD, Beck JD, Agústsdóttir $H$. Secondhand smoke and periodontal disease: atherosclerosis risk in communities study. Am J Public Health. 2011;101: S339-46.
62. Hutcherson JA, Scott DA, Bagaitkar J. Scratching the surface - tobacco-induced bacterial biofilms. Tob Induc Dis. 2015;13:1.

63. Silverstein P. Smoking and wound healing. Am J Med. 1992; 93(1A):22S-24S.

64. Alves LB, Costa PP, Scombatti de Souza SL, de Moraes Grisi MF, Palioto DB, Taba Jr M, Novaes Jr AB Jr. Acellular dermal matrix graft with or without enamel matrix derivative for root coverage in smokers: a randomized clinical study. J Clin Periodontol. 2012;39(4):393-399.

65. Eid HA, Syed S, Soliman AN. The role of gingival melanin pigmentation in inflammation of gingiva, based on genetic analysis. J Int Oral Health. 2013; 5(4):1-7.

66. Heikkinen T, Alvesalo L, Osborne RH, Pirttiniemi $P$. Maternal smoking and tooth formation in the foetus. I. Tooth crown size in the deciduous dentition. Early Hum Dev. 1992;30:49-49.

67. Heikkinen T, Alvesalo L, Osborne RH, Tienari J. Maternal smoking and tooth formation in the foetus. II. Tooth crown size in the permanent dentition. Early Hum Dev. 1994;40:73-86.

68.Dong $\mathrm{Q}$, Wu H, Dong G, Lou B, Yang L, Zhang $\mathrm{L}$. The morphology and mineralization of dental hard tissue in the offspring of passive smoking rats. Arch Oral Biol. 2011; 56(10):1005-13.

69.Avsar A, Topaloglu B, Hazar-Bodrumlu E. Association of passive smoking with dental development in young children. Eur $\mathrm{J}$ Paediatr Dent. 2013; 14(3):215-8.

70.Li Z, Liu J, Ye R, Zhang L, Zheng X, Ren A. Maternal passive smoking and risk of cleft lip with or without cleft palate. Epidemiology 2010; 21: $240-242$.

71. Rankin J. Second-hand smoke exposure and orofacial clefts. Paediatr Perinat Epidemiol. 2018; 32(5):428-429

Yazışma Adresi:

Solmaz MOBARAKI

Van Yüzüncü Yıl Üniversitesi

Diş Hekimliği Fakültesi

Pedodonti AD,

Van, Türkiye

Tel : +904322251744

E-mail : solmaz.mobaraki@gmail.com 